This is the author's final, peer-reviewed manuscript as accepted for publication. The publisher-formatted version may be available through the publisher's web site or your institution's library.

\title{
Emergence of novel reassortant H3N2 swine influenza viruses with the 2009 pandemic H1N1 genes in the United States
}

Qinfang Liu, Jingjiao Ma, Haixia Liu, Wenbao Qi, Joe Anderson, Steven C. Henry, Richard A. Hesse, Jürgen A. Richt, Wenjun Ma

\section{How to cite this manuscript}

If you make reference to this version of the manuscript, use the following information:

Liu, Q., Ma, J., Liu, H., Qi, W., Anderson, J., Henry, S. C., . . Ma, W. (2012).

Emergence of novel reassortant H3N2 swine influenza viruses with the 2009 pandemic H1N1 genes in the United States. Retrieved from http://krex.ksu.edu

\section{Published Version Information}

Citation: Liu, Q., Ma, J., Liu, H., Qi, W., Anderson, J., Henry, S. C., . . Ma, W. (2012). Emergence of novel reassortant H3N2 swine influenza viruses with the 2009 pandemic H1N1 genes in the United States. Archives of Virology, 157(3), 555-562.

Copyright: ( Springer-Verlag 2011

Digital Object Identifier (DOI): doi: 10.1007/s00705-011-1203-9

Publisher's Link: http://rd.springer.com/article/10.1007/s00705-011-1203-9

This item was retrieved from the K-State Research Exchange (K-REx), the institutional repository of Kansas State University. K-REx is available at http://krex.ksu.edu 


\title{
Emergence of novel reassortant $\mathrm{H} 3 \mathrm{~N} 2$ swine influenza viruses with the 2009 pandemic H1N1 genes in the United States
}

\author{
Qinfang Liu $\cdot$ Jingjiao Ma $\cdot$ Haixia Liu $\cdot$ Wenbao Qi $\cdot$ \\ Joe Anderson • Steven C. Henry $\cdot$ Richard A. Hesse • \\ Jürgen A. Richt $\cdot$ Wenjun Ma
}

Q. Liu $\cdot$ J. Ma $\cdot$ H. Liu $\cdot$ W. Qi $\cdot$ J. Anderson $\cdot$

R. A. Hesse - J. A. Richt · W. Ma (\&)

Department of Diagnostic Medicine and Pathobiology, Kansas State University, Mosier Hall, K233, Manhattan, KS 66506, USA

e-mail: wma@vet.k-state.edu

S. C. Henry

Abilene Animal Hospital PA, Abilene, KS 67410, USA

\begin{abstract}
Reassortant H1 swine influenza viruses (SIVs) carrying 2009 pandemic H1N1 virus (pH1N1) genes have been isolated from pigs worldwide. Seven novel reassortant H3N2 SIVs were identified from diseased pigs in the USA from winter 2010 to spring 2011. These novel viruses contain three or five internal genes from pH1N1 and con- tinue to circulate in swine herds. The emergence of novel reassortant H3N2 SIVs demonstrates reassortment between pH1N1 and endemic SIVs in pigs and justifies continuous surveillance. Since the first report on infection of pigs with the 2009 pandemic H1N1 virus (pH1N1) in Canada in 2009 [8], pH1N1 has been isolated from pigs throughout the world, including the USA [21]. Although pH1N1 was generated through reassortment of North American triple reassortant SIVs with the Eurasian avianlike H1N1 SIVs, to date, there is no evidence that the Eurasian avian-like H1N1 SIVs were ever isolated from US pigs. Introduction of $\mathrm{pH} 1 \mathrm{~N} 1$ into swine has raised concerns that novel reassor- tant viruses could be generated in pigs, that these reas- sortants might be more virulent and be transmitted more efficiently among humans than the parental viruses, and that they could cause the next pandemic. Reassortments of SIVs with pH1N1 in swine have been reported worldwide. The first reassortant H1N1 virus was found in Hong Kong, China, in 2009, and contained NA from pH1N1, HA from the Eurasian avian-like H1, and six internal genes from triple reassortant SIVs [22]. Subsequently, a reassortant H1N1 virus consisting of seven genes from pH1N1 and NA from endemic SIVs was isolated in pigs in Germany [18]. In early 2010, three reassortant H1N1 viruses containing NA from endemic H1N1 SIV and the remaining seven genes from pH1N1 were isolated from pigs in Thailand [10]. Recently, two reassortant H1N2 viruses were isolated from pigs in the UK and Italy; one contains six internal genes of $\mathrm{pH} 1 \mathrm{~N} 1$ and another isolate has $\mathrm{HA}$ and six internal genes of $\mathrm{pH} 1 \mathrm{~N} 1$ and the remaining genes from endemic SIVs [7, 15]. In the USA, nine H1N2 SIVs and one H1N1 reassortant SIV have been detected in swine herds from Indiana, Minnesota and North Carolina. All of these reassortant viruses contain the M gene and additional one to four internal genes from $\mathrm{pH} 1 \mathrm{~N} 1$ and the remaining genes from endemic triple reassortant SIVs [5, 20].

Here, we report the characterization of seven reassortant H3N2 SIVs containing internal genes from pH1N1. These novel reassortant H3N2 SIVs were isolated between winter of 2010 and spring of 2011 from five swine farms in the Midwestern USA in which outbreaks of respiratory disease had occurred. Genome analysis showed that six viruses contained NP, M and NS genes from pH1N1, and one isolate had PB2, PA, NP, M and NS from pH1N1 and the remaining genes from endemic H3N2 SIVs (Table 1).

In December 2010, an outbreak of respiratory disease occurred in nursery pigs in a commercial swine farm (farm \#1) in the Midwestern USA. In mid-January 2011, 50\% of the sows that provided piglets to farm \#1 (6000 sows in
\end{abstract}


Table 1 Reassortant patterns of novel H3N2 swine influenza viruses in the USA

\begin{tabular}{|c|c|c|c|c|c|c|c|c|c|}
\hline \multirow[t]{2}{*}{ Virus name } & \multirow[t]{2}{*}{ Subtype } & \multicolumn{8}{|c|}{ Gene segment } \\
\hline & & PB2 & PB1 & PA & HA & NP & NA & M & NS \\
\hline A/swine/Kansas/10-91088/2010 & $\mathrm{H} 3 \mathrm{~N} 2$ & $\mathrm{~T}$ & $\mathrm{~T}$ & $\mathrm{~T}$ & $\mathrm{~T}$ & $\mathrm{P}$ & $\mathrm{T}$ & $\mathrm{P}$ & $\mathrm{P}$ \\
\hline A/swine/Kansas/11-101926/2011 & $\mathrm{H} 3 \mathrm{~N} 2$ & $\mathrm{~T}$ & $\mathrm{~T}$ & $\mathrm{~T}$ & $\mathrm{~T}$ & $\mathrm{P}$ & $\mathrm{T}$ & $\mathrm{P}$ & $\mathrm{P}$ \\
\hline A/swine/Kansas/11-104465/2011 & $\mathrm{H} 3 \mathrm{~N} 2$ & $\mathrm{~T}$ & $\mathrm{~T}$ & $\mathrm{~T}$ & $\mathrm{~T}$ & $\mathrm{P}$ & $\mathrm{T}$ & $\mathrm{P}$ & $\mathrm{P}$ \\
\hline $\mathrm{A} /$ swine/Kansas/11-104467/2011 & $\mathrm{H} 3 \mathrm{~N} 2$ & $\mathrm{~T}$ & $\mathrm{~T}$ & $\mathrm{~T}$ & $\mathrm{~T}$ & $\mathrm{P}$ & $\mathrm{T}$ & $\mathrm{P}$ & $\mathrm{P}$ \\
\hline $\mathrm{A} /$ swine/Kansas/11-107824/2011 & $\mathrm{H} 3 \mathrm{~N} 2$ & $P$ & $\mathrm{~T}$ & $\mathrm{P}$ & $\mathrm{T}$ & $\mathrm{P}$ & $\mathrm{T}$ & $\mathrm{P}$ & $\mathrm{P}$ \\
\hline A/swine/Kansas/11-109700/2011 & $\mathrm{H} 3 \mathrm{~N} 2$ & $\mathrm{~T}$ & $\mathrm{~T}$ & $\mathrm{~T}$ & $\mathrm{~T}$ & $\mathrm{P}$ & $\mathrm{T}$ & $\mathrm{P}$ & $\mathrm{P}$ \\
\hline A/swine/Kansas/11-110529/2011 & $\mathrm{H} 3 \mathrm{~N} 2$ & $\mathrm{~T}$ & $\mathrm{~T}$ & $\mathrm{~T}$ & $\mathrm{~T}$ & $\mathrm{P}$ & $\mathrm{T}$ & $\mathrm{P}$ & $\mathrm{P}$ \\
\hline
\end{tabular}

PB, polymerase basic protein; PA, polymerase acidic protein; HA, hemagglutinin; NP, nucleoprotein, NA, neuraminidase; M, matrix; NS, nonstructural; T: gene has closest homology with triple reassortant swine influenza virus; P: gene has closest homology with 2009 pandemic H1N1 virus

sow farm \#1) were sick with acute respiratory signs, and more than 100 sows were suddenly dead within 24 hours after the occurrence of clinical signs. Subsequently, in February 2011, one independent farm (farm \#2) located in the same area and farm \#1 had an outbreak of respiratory disease in nursery pigs; both received piglets from sow farm \#1. In mid-March 2011, an outbreak of respiratory disease occurred in nursery pigs in another independent farm (farm \#3) that does not purchase piglets from sow farm \#1. At the beginning of April 2011, farm \#2 and another independent farm (farm \#4) had an outbreak of respiratory disease in nursery pigs, and both farms had purchased piglets from the sow farm \#1. During the outbreak, pigs showed respiratory signs, such as coughing, sneezing and nasal discharge. The morbidity was high (Г60\%) and the mortality was rather low (3\%) in the affected herds. The infection persisted in the swine herds throughout the winter in all affected farms. At necropsy, the attending veterinarian observed gross lesions of pneu- monia suggestive of influenza. Lung tissues and nasal swab samples from diseased pigs were submitted to the Kansas State Veterinary Diagnostic Laboratory (KSVDL). SIVs were detected and isolated from samples collected from diseased pigs of all five farms (1 sow farm and 4 nursery farms) by standard real-time RT-PCR and virus isolation in the KSVDL. Lung tissues from these pigs were also found to be positive for porcine circovirus type 2 and Strepto- coccus suis. Porcine reproductive and respiratory syndrome virus was detected in lung tissues of pigs from two affected nursery farms (farm \#1 and \#2). All seven SIVs were isolated in cell culture using MDCK cells and identified to be of the H3N2 subtype by hemagglutinin inhibition and gel-based RT-PCR assays using standard methods. All isolates were negative by pH1N1 NA-gene specific real- time RT-PCR and positive by pH1N1 M-gene specific real- time RT-PCR [12]. The full genome sequences of all seven isolates were obtained by sequencing all eight gene segments (sequence primers are available upon request). BLAST (http://blast.ncbi.nlm.nih.gov) and phylogenetic tree (MegAlign software version 4.1) analyses were con- ducted to determine the source of the individual genes from the isolates.

Based on sequence analysis, seven H3N2 isolates were identified to be reassortants of pH1N1 and endemic H3N2 SIVs. Phylogenetic analysis revealed that the NP, M and NS genes of all seven novel H3N2 reassortant viruses grouped within the pH1N1 cluster. The PB2 and PA genes of A/swine/Kansas/11-107824/2011 isolated from farm \#3 also clustered into the pH1N1 group. The HA genes of these seven viruses belonged to the North American triple reassortant H3N2 virus lineage. The NA gene of A/swine/ Kansas/11-110529/2011 isolated from farm \#4 grouped within the human-like lineage, whereas the NA genes of the other $6 \mathrm{H} 3 \mathrm{~N} 2$ isolates clustered into the North Amer- ican triple reassortant H3N2 lineage. In addition, all of the other internal genes that are not $\mathrm{pH} 1 \mathrm{~N} 1$-like were grouped within the triple reassortant SIVs cluster (Fig. 1). Based on the HA phylogenetic tree, the H3N2 triple reassortant viruses in the field are genetically diverse (Fig. 1), because four genetic clusters of H3N2 viruses are circulating presently in US swine herds. These genetically different $\mathrm{H} 3 \mathrm{~N} 2$ viruses were generated by reassortment events due to at least three introductions of different seasonal human H3N2 viruses into the swine herds in the late 1990s [16, 23, 24].

Molecular analysis showed that the M2 protein of all seven novel reassortant H3N2 viruses had an S31N amantadine-resistance mutation, similar to $\mathrm{pH} 1 \mathrm{~N} 1$ viruses; the NS1 gene of these seven viruses encodes a truncated 220-amino-acid protein that is identical to $\mathrm{pH} 1 \mathrm{N1}$ NS1. There were no specific mutations for adaptation to mam- malian hosts $(627 \mathrm{E}$ and 701D) $[6,11,19]$ in the PB2 of any of the seven novel reassortant H3N2 viruses, but they all had a 271A and SR polymorphism at positions 590/591, 
Fig. 1 Phylogenetic trees of the PB2, PB1, PA, HA, NP, NA, M and NS genes of the seven reassortant $\mathrm{H} 3 \mathrm{~N} 2 \mathrm{SIV}$ s. The tree was generated by the distancebased neighbor-joining method in the software MEGA 4.1. The reliability of the tree was assessed by bootstrap analysis with 1,000 replications.

Horizontal distances are proportional to genetic distance. The viruses isolated in this study are in italic and bold. The viruses (H3N2) that infected two children in Pennsylvania and Indiana are in bold

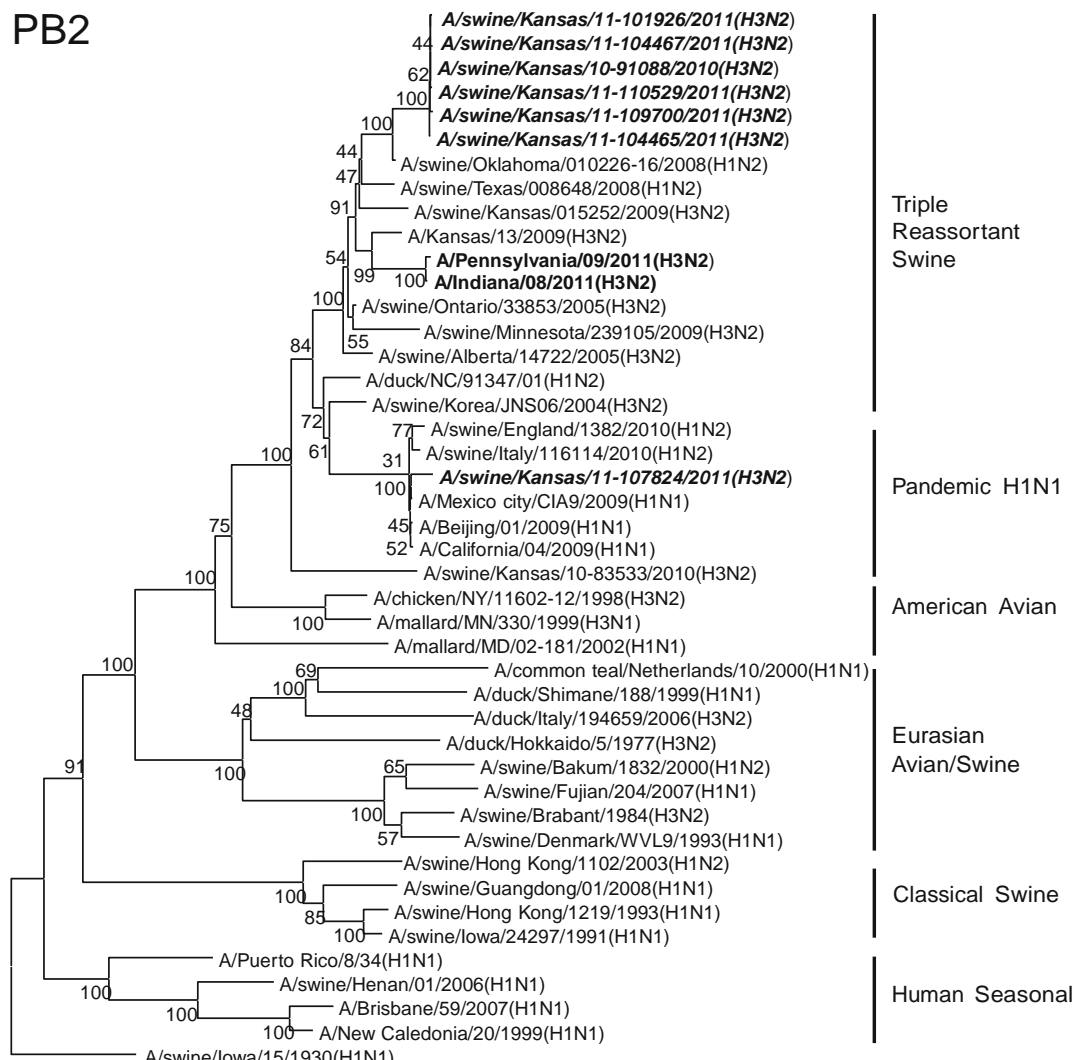

0.02

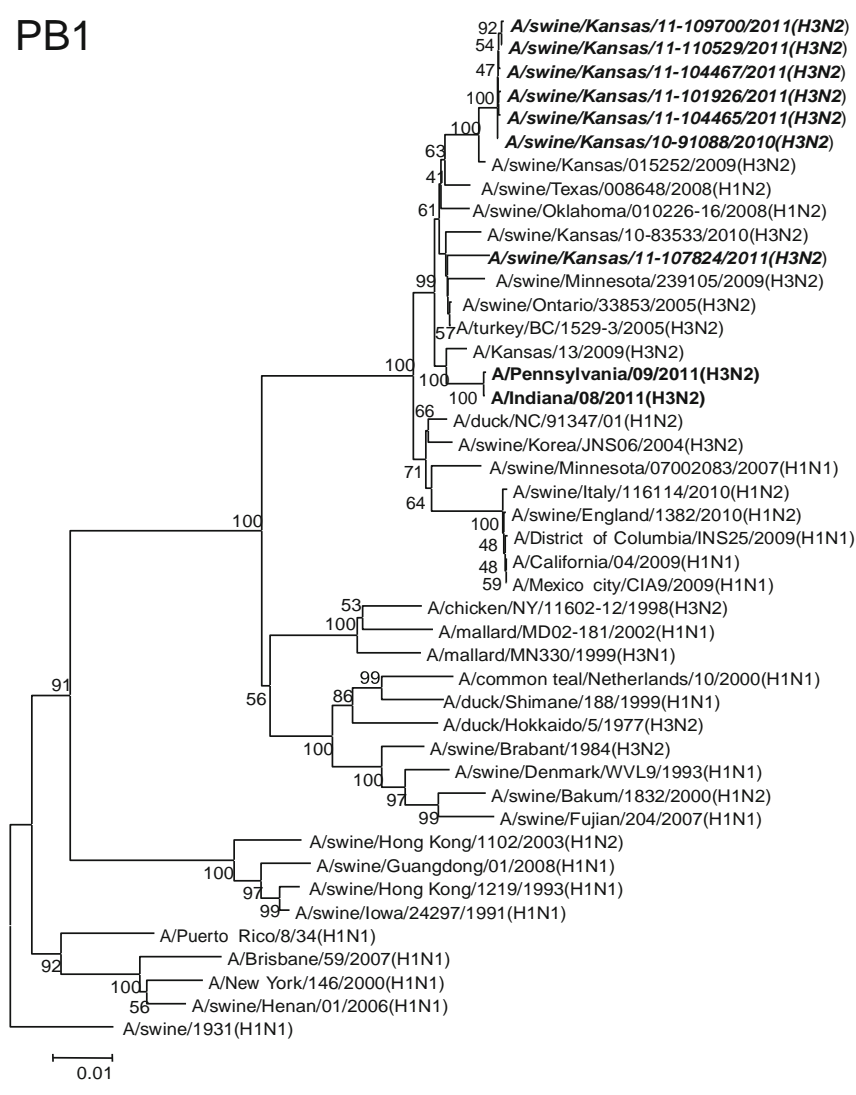

Triple

Reassortant

Swine

Pandemic H1N1

Eurasian

Avian/Swine

Classical Swine

Human Seasonal 
Fig. 1 continued

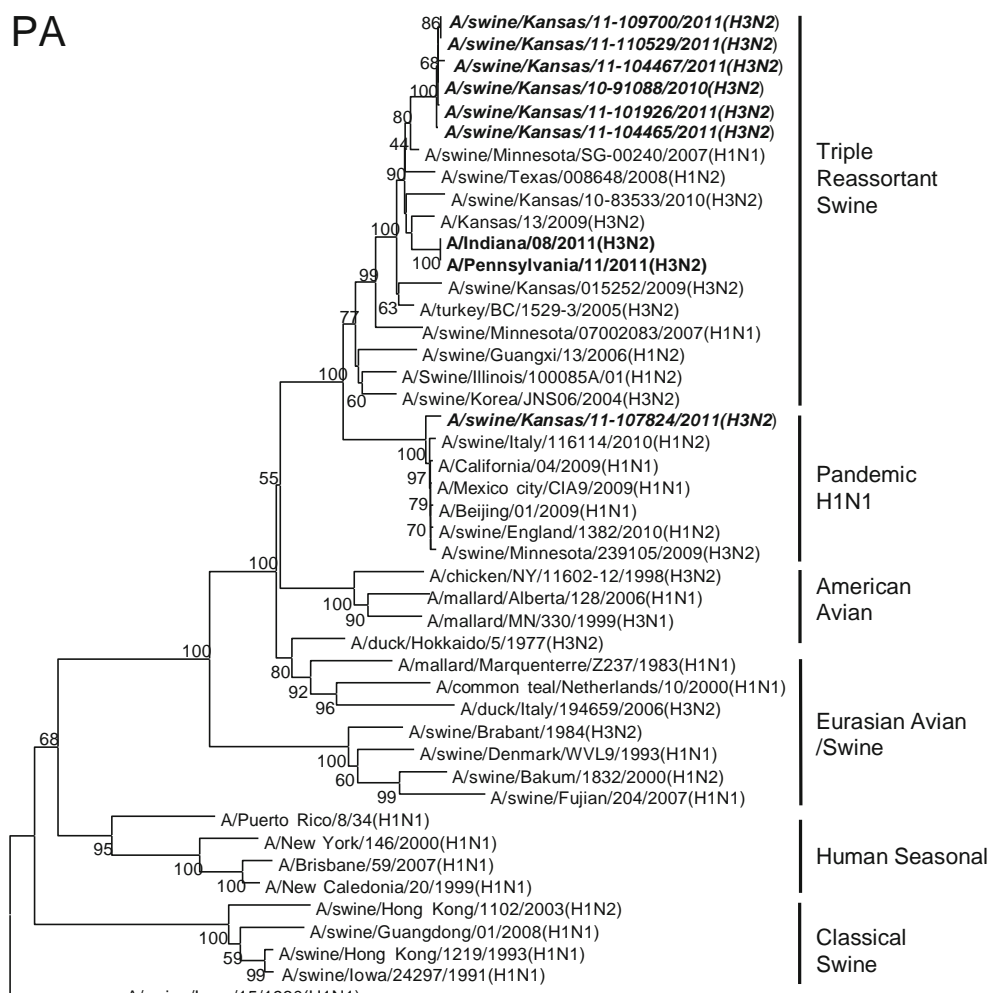

$\longmapsto 0.02$

$\mathrm{HA}$
99- A/swine/lowa/24297/1991(H1N1)

Swine
Triple Reassortant Swine

Human-like

European Swine

American Avian

Eurasian Avian

83 A/chicken/Laos/A0573/2007(H3N8)

A/Hong Kong/68(H3N2)

$\mathrm{A} /$ mallard/Netherlands/1/2007(H3N2) 
Fig. 1 continued

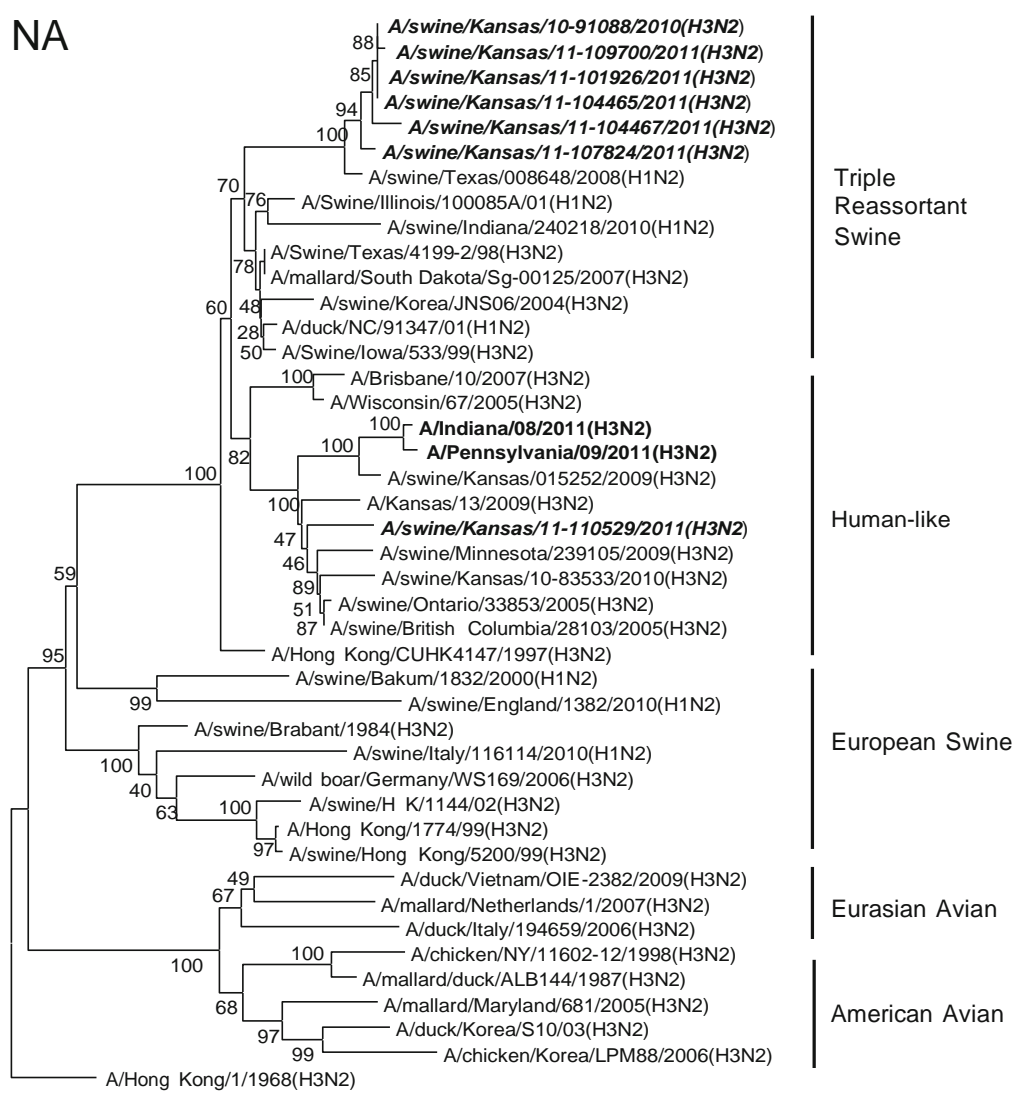

0.02

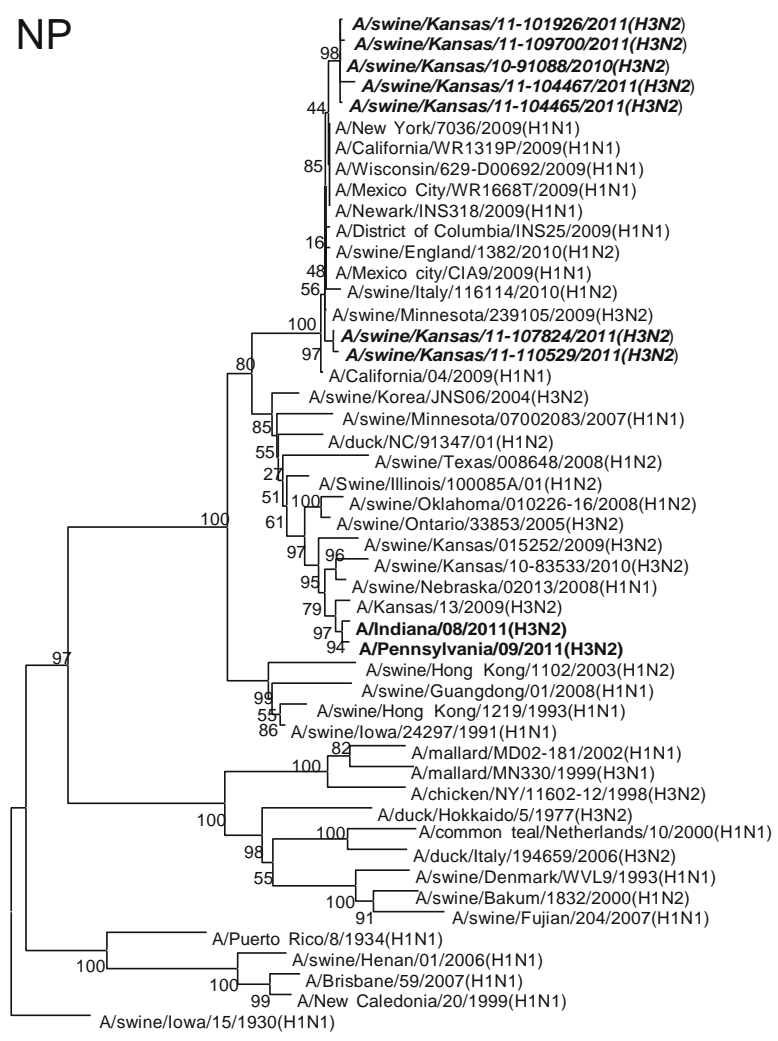

Pandemic H1N1

Triple

Reassortant

Swine

Classical Swine

American Avian

Eurasian Avian/Swine

Human Seasonal 
Fig. 1 continued

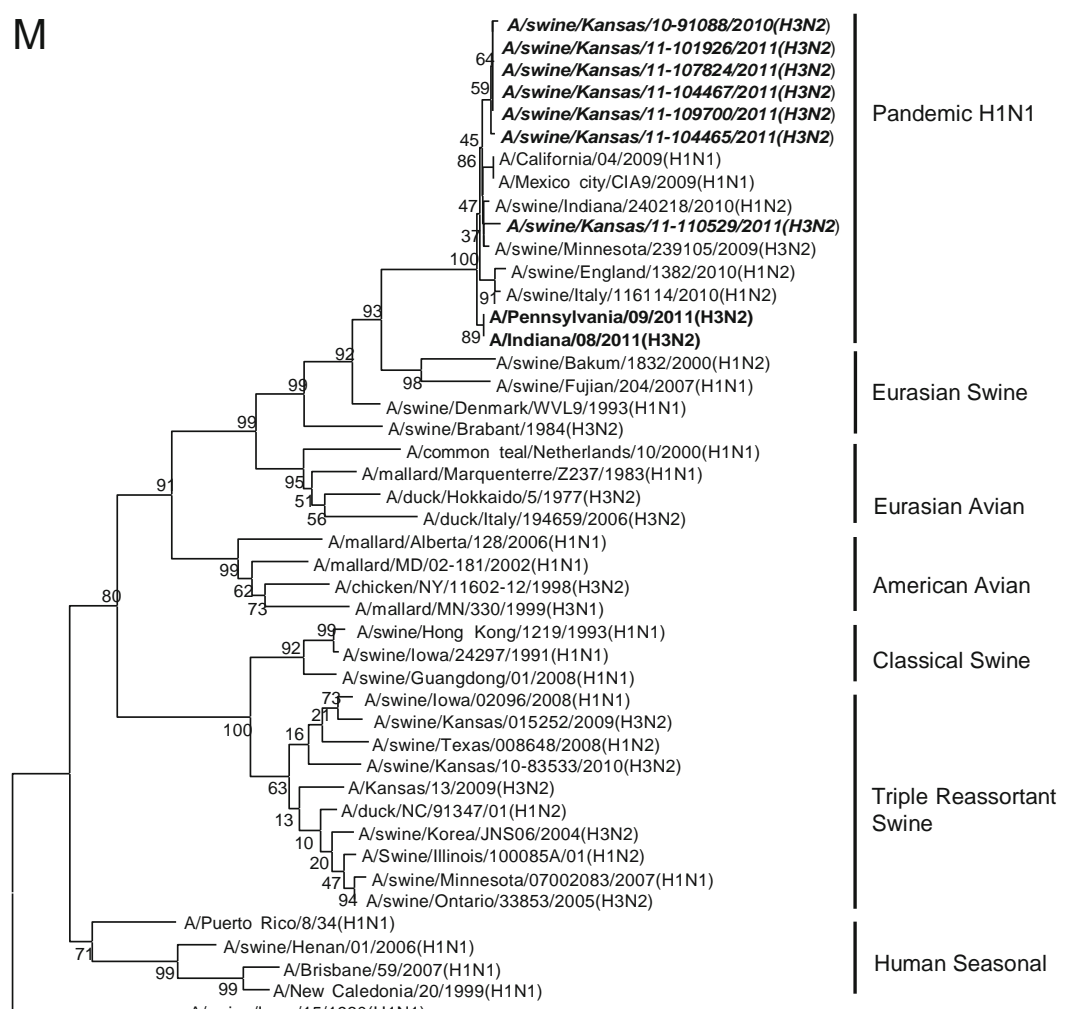

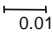

NS

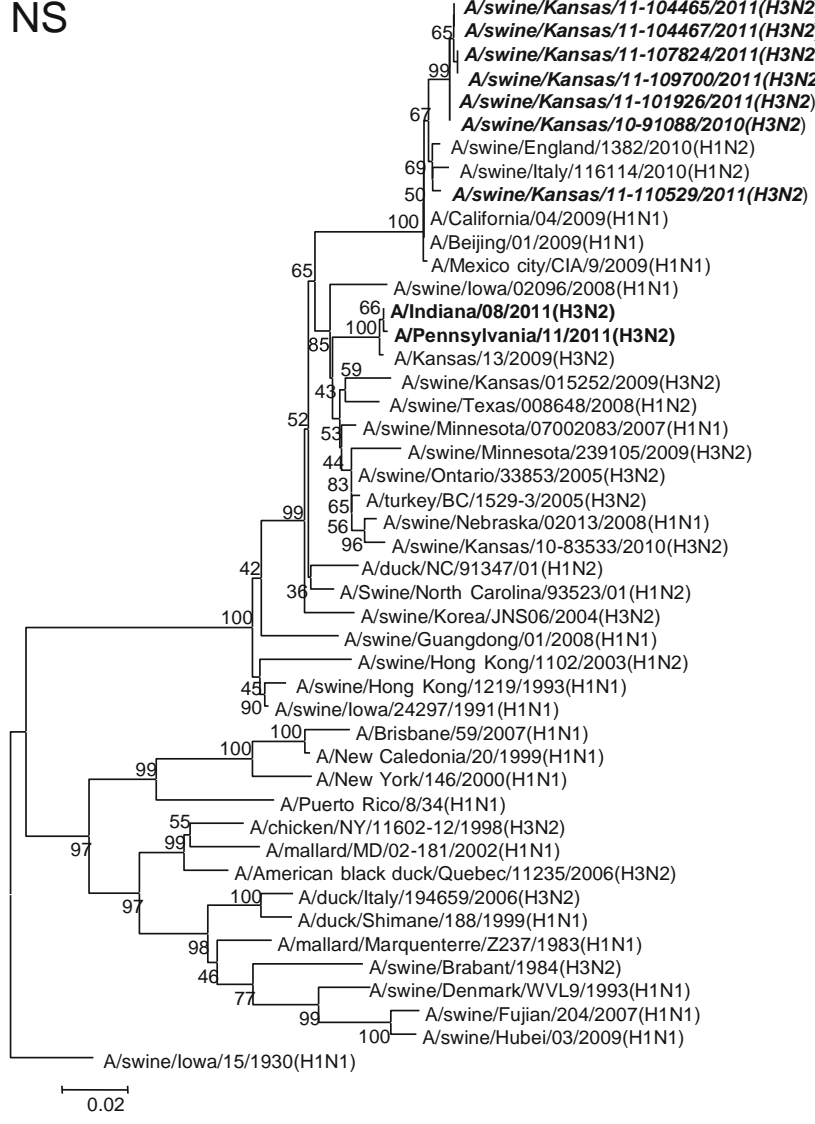

Pandemic H1N1

Triple Reassortant

Swine

Classical Swine

Human Seasonal

American Avian

Eurasian Avian

Eurasian Swine 
which is believed to compensate for the lack of $627 \mathrm{~K}[2,14]$. The HA proteins of all seven H3N2 viruses had $226 \mathrm{~V}$ and $228 \mathrm{~S}$ at the receptor-binding sites except for the HA of the isolate A/swine/Kansas/11-107824/2011, which con- tained 226V and 228G. The H3 HA receptor-binding site combination 226V/228S is different from those of most avian (226Q/228G) and human (226L/228S) influenza virus HAs [13], but it is present in the majority of HAs ([90\%) of North American triple reassortant H3N2 SIVs. The 226V/228G combination in the HA receptor-binding site is rarely found. The receptor specificity of the $226 \mathrm{~V} / 228 \mathrm{~S}$ and $226 \mathrm{~V} / 228 \mathrm{G}$ combinations remains unknown and needs to be investigated in the future. In addition, the NA protein had 119E, 292R and 274H, suggesting suscepti- bility to oseltamivir.

$\mathrm{H} 1$ subtype (i.e., H1N1 and $\mathrm{H} 1 \mathrm{~N} 2$ ) reassortants of $\mathrm{pH} 1 \mathrm{~N} 1$ and endemic SIVs have been isolated from pigs worldwide $[5,7,10,15,18,20,22]$. A reassortant H3N2 SIV was only recently isolated from Minnesotan pigs and had PA, NP and M genes from the $\mathrm{pH} 1 \mathrm{~N} 1$ [5]. In this report, seven novel $\mathrm{H} 3 \mathrm{~N} 2$ reassortants were isolated from diseased pigs from five different farms. Six of the H3N2 viruses had a similar genetic constellation, i.e., NP, M and NS were derived from pH1N1, and the remaining genes were from endemic H3N2 SIVs; one isolate had PB2, PA, NP, M and NS from pH1N1 and the remaining genes from endemic H3N2 triple reas- sortant SIVs. Three reassortant H1N2 SIVs containing a similar genetic constellation, carrying the $\mathrm{pH} 1 \mathrm{~N} 1 \mathrm{NP}, \mathrm{M}$ and NS genes, were recently detected in pigs [5], indicating that this genotype of novel reassortant SIVs seems to be preferred in different subtypes and seem to be stable. The novel reas- sortant H3N2 viruses having pH1N1 NP, M and NS genes were isolated from diseased sows (sow farm \#1) and nursery pigs from three farms (farms \#1, \#2 and \#4) that obtained piglets from sow farm \#1, indicating that the piglets may have been infected at the sow farm before transportation to the nursery. Importantly, similar H3N2 reassortant viruses were also isolated from farms \#1 and \#2 at later time points (two months after the first isolations occurred), suggesting that the virus had been established and continued to circulate within the affected production systems. An H3N2 isolate containing all internal genes from pH1N1 except PB1 was isolated from another farm (farm \#3); this farm does not receive piglets from sow farm \#1. Whether novel H3N2 reassortant viruses have increased pathogenicity and are transmitted among pigs more efficiently than pH1N1 or parental H3N2 SIVs remains unknown; the role of internal genes from $\mathrm{pH} 1 \mathrm{~N} 1$ in pathogenesis and transmissibility of these novel viruses need to be investigated.

Concurrent epidemiological surveillance has revealed that these novel reassortant H3N2 SIVs are circulating in Midwest swine herds although triple reassortant H1N1, H1N2 and H3N2 SIVs have also been isolated from other swine farms in the same area. A Kansas boy who was in contact with healthy pigs while attending a county fair in 2009 was reported to have been infected with a triple reassortant H3N2 SIV. This H3N2 virus does not seem to be transmitted efficiently among humans because his three household contacts did not show signs of illness [4]. Recently, two younger children from Indiana and Pennsyl- vania were infected by reassortant H3N2 SIVs that contained only the $M$ gene from pH1N1 [3]. Two other children in Pennsylvania who were directly exposed to swine at an agricultural fair had confirmed infection with a similar pH1N1 reassortant H3N2 influenza virus [1]. Although no reported human illness due to influenza infection was asso- ciated with the Kansas farms where the novel reassortant H3N2 viruses were isolated, it remains unclear whether these novel reassortant H3N2 SIVs can be transmitted to and infect humans. If so, they most likely will pose a threat, especially to children born after 1998, due to the lack of immunity to these viruses. Notably, the isolate $\mathrm{A} /$ swine/Kansas/11-110529/2011 has an NA gene that is similar to those of human H3N2 viruses, including the novel reassortant H3N2 viruses that recently infected children in Indiana and Penn- sylvania [1,3]. Although the NA is grouped within the human-like H3N2 influenza lineage, North American triple reassortant SIVs containing a similar NA gene have been circulating in US swine herds for more than 5 years. Nev- ertheless, continuous circulation of pH1N1 in swine will increase the chance of further reassortment with human, avian or swine influenza viruses $[9,17,22]$ and could result in a novel virus with the potential to cause infection and efficient transmission among humans. In conclusion, the emergence of novel reassortant H3N2 SIVs in US swine is further evidence of reassortment between pH1N1 and endemic SIVs. The occurrence of human infection with novel reassortant $\mathrm{H} 3 \mathrm{~N} 2$ viruses $[1,3]$ warrants continuous surveillance in swine and humans.

GenBank accession numbers: JN409388-JN409443

Acknowledgments This study was partially supported by a grant from the National Institute of Allergy and Infectious Diseases, National Institute of Health, Department of Health and Human Ser- vices (Contract No. HHSN266200700005C), and by CEEZAD pro- gram of the Department of Homeland Security (Cooperative Agreement No. 2010-ST-061-AG000102). 


\section{References}

1. Pennsylvania Department of Health (Sept 5, 2011) Novel influ- enza-A cases linked to county fair; Pennsylvanians should con- tinue flu prevention practices and report flu-like illness

2. Bussey KA, Bousse TL, Desmet EA, Kim B, Takimoto T (2010) PB2 residue 271 plays a key role in enhanced polymerase activity of influenza A viruses in mammalian host cells. J Virol 84: 4395-4406

3. Centers for Disease Control and Prevention (2011) Swine-origin influenza A (H3N2) virus infection in two children-Indiana and Pennsylvania. Morb Mortal Wkl Rep (MMWR) 60:1213-1215

4. Cox CM, Neises D, Garten RJ, Bryant B, Hesse RA, Anderson GA, Trevino-Garrison I, Shu B, Lindstrom S, Klimov AI, Finelli L (2011) Swine influenza virus A (H3N2) infection in human, Kansas, USA, 2009. Emerg Infect Dis 17:1143-1144

5. Ducatez MF, Hause B, Stigger-Rosser E, Darnell D, Corzo C, Juleen K, Simonson R, Brockwell-Staats C, Rubrum A, Wang D, Webb A, Crumpton JC, Lowe J, Gramer M, Webby RJ (2011) Multiple reassortment between pandemic (H1N1) 2009 and endemic influenza viruses in pigs, United States. Emerg Infect Dis 17:1624-1629

6. Gabriel G, Dauber B, Wolff T, Planz O, Klenk HD, Stech J (2005) The viral polymerase mediates adaptation of an avian influenza virus to a mammalian host. Proc Natl Acad Sci USA 102:18590-18595

7. Howard WA, Essen SC, Strugnell BW, Russell C, Barass L, Reid SM, Brown IH (2011) Reassortant pandemic (H1N1) 2009 virus in pigs, United Kingdom. Emerg Infect Dis 17:1049-1052

8. Howden KJ, Brockhoff EJ, Caya FD, McLeod LJ, Lavoie M, Ing JD, Bystrom JM, Alexandersen S, Pasick JM, Berhane Y, Morrison ME, Keenliside JM, Laurendeau S, Rohonczy EB (2009) An investigation into human pandemic influenza virus (H1N1) 2009 on an Alberta swine farm. Can Vet J 50:1153-1161

9. Kimble JB, Sorrell E, Shao H, Martin PL, Perez DR (2011) Compatibility of H9N2 avian influenza surface genes and 2009 pandemic H1N1 internal genes for transmission in the ferret model. Proc Natl Acad Sci USA 108:12084-12088

10. Kitikoon P, Sreta D, Nuntawan Na Ayudhya S, Wongphatchar- achai M, Lapkuntod J, Prakairungnamthip D, Bunpapong N, Suradhat S, Thanawongnuwech R, Amonsin A (2011) Brief report: molecular characterization of a novel reassorted pandemic H1N1 2009 in Thai pigs. Virus Genes. doi:10.1007/s11262-11011-10597-11265

11. Li Z, Chen H, Jiao P, Deng G, Tian G, Li Y, Hoffmann E, Webster RG, Matsuoka Y, Yu K (2005) Molecular basis of replication of duck H5N1 influenza viruses in a mammalian mouse model. J Virol 79:12058-12064

12. Ma W, Oberst R, Li X, Clouser D, Hesse R, Rowland R, Richt JA (2010) Rapid detection of the pandemic 2009 H1N1 virus M gene by realtime and gel-based RT-PCR assays. Influenza Other Respi Viruses 4:397-403

13. Matrosovich MN, Gambaryan AS, Teneberg S, Piskarev VE, Yamnikova SS, Lvov DK, Robertson JS, Karlsson KA (1997) Avian influenza A viruses differ from human viruses by recog- nition of sialyloligosaccharides and gangliosides and by a higher conservation of the HA receptor-binding site. Virology 233: 224-234

14. Mehle A, Doudna JA (2009) Adaptive strategies of the influenza virus polymerase for replication in humans. Proc Natl Acad Sci USA $106: 21312-21316$

15. Moreno A, Di Trani L, Faccini S, Vaccari G, Nigrelli D, Boniotti MB, Falcone E, Boni A, Chiapponi C, Sozzi E, Cordioli P (2011) Novel H1N2 swine influenza reassortant strain in pigs derived from the pandemic H1N1/2009 virus. Vet Microbiol 149: 472-477

16. Richt JA, Lager KM, Janke BH, Woods RD, Webster RG, Webby RJ (2003) Pathogenic and antigenic properties of phylogeneti- cally distinct reassortant H3N2 swine influenza viruses cocircu- lating in the United States. J Clin Microbiol 41:3198-3205

17. Schrauwen EJ, Herfst S, Chutinimitkul S, Bestebroer TM, Rim-melzwaan GF, Osterhaus AD, Kuiken T, Fouchier RA (2011) Possible increased pathogenicity of pandemic (H1N1) 2009 influenza virus upon reassortment. Emerg Infect Dis 17:200-208

18. Starick E, Lange E, Fereidouni S, Bunzenthal C, Hoveler R, Kuczka A, grosse Beilage E, Hamann HP, Klingelhofer I, Steinhauer D, Vahlenkamp T, Beer M, Harder T (2011) Reas- sorted pandemic (H1N1) 2009 influenza A virus discovered from pigs in Germany. J Gen Virol 92:1184-1188

19. Subbarao EK, London W, Murphy BR (1993) A single amino acid in the PB2 gene of influenza A virus is a determinant of host range. J Virol 67:1761-1764 
20. Sun D, Schwartz KJ, Janke GH, Haney D, Block S, Yoon KJ (2011) Occurrence of novel reassortants between North American swine influenza virus and pandemic 2009 H1N1 virus in US swine. In: American Society for Virology 30th Annual Meeting, University of Minnesota, Minneapolis, p 221

21. UDSA (2010) 2009 Pandemic H1N1 Influenza presumptive and confirmed results (January 19, 2010)

22. Vijaykrishna D, Poon LL, Zhu HC, Ma SK, Li OT, Cheung CL, Smith GJ, Peiris JS, Guan Y (2010) Reassortment of pandemic H1N1/2009 influenza A virus in swine. Science 328:1529

23. Vincent AL, Ma W, Lager KM, Janke BH, Richt JA (2008) Swine influenza viruses a North American perspective. Adv Virus Res $72: 127-154$

24. Webby RJ, Rossow K, Erickson G, Sims Y, Webster R (2004) Multiple lineages of antigenically and genetically diverse influ- enza A virus co-circulate in the United States swine population. Virus Res 103:67-73 